\title{
A SOCIEDADE DA INFORMAÇÃO A SERVIÇO DA INCLUSÃO SOCIAL
}

\author{
MARIA CRISTINA CERESER PEZZELLA ${ }^{1}$ \\ MICHELLE DIAS BUBLITZ ${ }^{2}$
}

\begin{abstract}
RESUMO: A sociedade moderna está caracterizada por um processo de evolução tecnológica que transformou os meios de comunicação pela velocidade no acesso às informações. A Sociedade da Informação distingue nosso tempo com a marca da inovação e da instantaneidade, mas esbarra, à medida que cresce, num imenso desafio: precisa universalizar-se, democratizar-se, sob pena de reproduzir e perpetuar os velhos limites de um mundo historicamente desigual. O teletrabalho é compreendido como uma nova forma de prestar serviços na Era das novas tecnologias. Enfrentar-se-á, a partir das premissas acima, as questões pertinentes a formação profissional e a educação face ao uso das tecnologias da informação e comunicação. $\mathrm{O}$ artigo pretende averiguar aspectos relacionados ao estágio atual de desenvolvimento da Sociedade da Informação no Brasil, com ênfase para o debate sobre o uso das tecnologias da informação e comunicação como instrumento de redução das desigualdades sociais, uma vez que informação e comunicação são segmentos praticamente indissociáveis. PALAVRAS-CHAVE: Sociedade da Informação; Igualdade; Inclusão Social.
\end{abstract}

Artigo recebido em 07.08.2011. Pareceres emitidos em 16.12.2011 e 01.06.2012.

Artigo aceito para publicação em 17.06.2012.

${ }^{1}$ Advogada. Professora do Programa de Pesquisa e Extensão e Pós-Graduação em Direito da Universidade do Oeste de Santa Catarina - UNOESC. Coordenadora/Líder do Grupo de Pesquisas (CNPq) intitulado "Direitos Fundamentais Civis: A Ampliação dos Direitos Subjetivos", sediado na UNOESC. Graduada em Direito pela Pontifícia Universidade Católica do Rio Grande do Sul PUCRS (1988). Mestre em Direito pela Universidade Federal do Rio Grande do Sul - UFRGS (1998). Doutora em Direito pela Universidade Federal do Paraná - UFPR (2002). Avaliadora do INEP/MEC e Supervisora do SESu/MEC. Endereço de acesso ao banco de currículos do sistema lattes/URL: http://lattes.cnpq.br/7386742048598458.crispezzella@uol.com.br

${ }^{2}$ Advogada. Mestranda em Direito pela Pontifícia Universidade Católica do Rio Grande do Sul PUCRS, bolsista CAPES. Especialista em Direito e Processo do Trabalho pela Faculdade IDC Instituto de Desenvolvimento Cultural (2009). Graduada pela Universidade Luterana do Brasil ULBRA - campus Canoas/RS (2008). Integrante qualificada como Pesquisadora do Grupo de Estudos e Pesquisas (CNPq) intitulado "Direitos Fundamentais Civis: A Ampliação dos Direitos Subjetivos", sediado na Universidade do Oeste de Santa Catarina - UNOESC, sob coordenação da Profa. Dra. Maria Cristina Cereser Pezzella. Integrante qualificada como Pesquisadora do Grupo de Estudos e Pesquisas (CNPq) intitulado "Novas Tecnologias e Relações de Trabalho" sob coordenação da Dra. Profa. Denise Pires Fincato, sediado na PUCRS. Integrante qualificada como Estudante do Grupo de Estudos e Pesquisas em Direitos Fundamentais (CNPq) sob coordenação do Dr. Prof. Ingo Wolfgang Sarlet e do Dr. Prof. Carlos Alberto Molinaro - PUCRS. Endereço de acesso ao banco de currículos do sistema lattes/URL: http://lattes.cnpq.br/5250389607028753. michellebublitz@gmail.com 
ABSTRACT: Modern society is characterized by a process of technological evolution that has transformed the media by the speed of access to information. The Information Society distinguishes our time with the brand of innovation and immediacy, but coming up, as it grows, a huge challenge: it must be universal, democratizing, failing to reproduce and perpetuate the old boundaries of a world historically uneven. Telework is understood as a new way to deliver services in the era of new technologies. Addressing it will, from the premises above, the issues pertaining to training and education over the use of information technology and communication. The article aims to examine issues related to the current stage of development of the Information Society in Brazil, with emphasis on the debate over the use of information technology and communication as an instrument for reducing social inequalities, since information and communication segments are practically inseparable.

KEYWORDS: Information Society; Equality; Social Inclusion.

SUMÁRIO: Introdução; 1 A Sociedade da Informação sob a Perspectiva da Exclusão e Inclusão; 2 Teletrabalho como nova forma de Prestar Serviços na Era das Novas Tecnologias; 3 Formação Profissional e Educação face ao uso das Tecnologias da Informação e Comunicação; 4 Controvérsias sobre a Necessidade de Universalização das Tecnologias da Informação e Comunicação; 5 A Sociedade da Informação a Serviço da Inclusão Social; Considerações Finais; Referências Bibliográficas.

SUMMARY: Introduction; 1 The Information Society from the Perspective of Exclusion and Inclusion; 2 Telework as a new way to Deliver Services in the Era of New Technologies; 3 Vocational Training and Education against the use of Information and Communication Technologies; 4 Controversies about the Necessity of Universal Information Technology and Communication; 5 The Information Society in the Service of Social Inclusion; Conclusion; Bibliographical References.

\section{INTRODUÇÃO}

A sociedade não é um elemento estático, muito pelo contrário, está em constante mutação, e como tal, está inserida num processo de mudança em que as novas tecnologias são as principais responsáveis. Identifica-se um novo paradigma de sociedade que se baseia num bem precioso, a informação, atribuindo-Ihe várias designações, entre elas a Sociedade da Informação.

O desenvolvimento tecnológico avança em velocidade tamanha, principalmente nos últimos tempos, que é impossível o ser humano acompanhá-lo, ou seja, a capacidade de invenção do ser humano jamais vai chegar a acompanhar a capacidade de desenvolvimento tecnológico, sendo que eles nunca andaram juntos. Acredita-se que no futuro, caso não seja tomada nenhuma medida para incluir os analfabetos digitais, diante da tamanha e veloz evolução tecnológica, não terão o que fazer no mercado de trabalho, por não conseguirem, ou na grande maioria das vezes não terem chances, de andar passo a passo com o desenvolvimento. É evidente que o desenvolvimento tecnológico é resultado do trabalho humano, mas apenas e tão somente alguns possuem capacidade tecnológica e econômica para usufruir dessas riquezas potenciais. O que o artigo pretende enfrentar é o 
hiato da criação com a fruição desses bens, como forma de demonstrar a questão atinente a desigualdade de oportunidades.

Diante dessa evolução, é de caráter urgente as medidas que devem ser tomadas no sentido de dar oportunidade e tempo para que as pessoas excluídas do mundo da informação possam se qualificar.

Vive-se em uma época que o ser humano com capacidade de raciocinar que ignora ou indispõe de possibilidades para o uso das tecnologias da informação e comunicação estará fadado a total exclusão digital e consequentemente, em um futuro próximo, sofrerá a exclusão social. Esta conclusão deve-se ao raciocínio lógico que implica dizer que a exclusão digital acarreta a econômica e a social. Estamos diante de um raciocínio lógico.

Portanto, a inclusão digital pode ser considerada como um processo facilitador no desenvolvimento e auxílio da promoção da educação, inserção no mercado de trabalho, desenvolvimento da economia e inclusão social.

Impossível falar em inclusão digital sem falar em telecentros. A partir dos telecentros a população menos favorecida economicamente poderia ter acesso e contato com algum tipo de tecnologia, na tentativa de diminuir a distância existente entre aqueles que detêm a informação por possuírem acesso mais direto à tecnologia e aqueles que se mantêm à sua margem.

Embora existam entraves ao incremento da inclusão digital em nosso país, é necessária a adoção de políticas públicas voltadas a este objetivo, sob pena de criarmos em pouco tempo um abismo quase intransponível entre a população brasileira, ou seja, os alfabetizados digitalmente e os excluídos digitais.

É bom esclarecer que a inclusão digital está intimamente ligada a inclusão social, pelo fato de haver uma democratização do acesso à informação disponibilizando tecnologia à população. Cabe ressaltar que o principal objetivo não é disponibilizar a tecnologia em si, mas sim a integração do indivíduo excluído digitalmente na sociedade, eis que considerada a mola propulsora de condições de trabalho e sobrevivência no mudo capitalista em que vivemos.

1 A SOCIEDADE DA INFORMAÇÃO SOB A PERSPECTIVA DA EXCLUSÃO E INCLUSÃO

O espaço virtual, cada vez mais, vai se tornando a grande biblioteca da humanidade, no qual estão inseridos, não somente os livros escritos, ao longo da história da humanidade, mas, também, nossa forma de viver e conviver. Para esse espaço, de forma gradativa e dinâmica, está sendo conduzida nossa vida social, política e econômica, assim como nossos bens simbólicos e nossa cultura.

O termo nossa não se relaciona a uma situação local, mas sim a uma situação planetária, ou seja, o ciberespaço faz com que o mundo seja 
percebido com uma dimensão completamente nova, de unicidade, eliminando as fronteiras de Estado-nação ${ }^{3}$.

As distâncias são encurtadas e o tempo ${ }^{4}$ passa a ter uma nova concepção. $\mathrm{O}$ ato da busca do saber que, até o final do século $\mathrm{XX}$, restringia-se, basicamente, à educação presencial e promovida pela tecnologia a qual denominamos livro, passa por uma modificação profunda. A dinâmica que as infovias ${ }^{5}$ estabelecem nas trocas de informação e nas comunicações impacta nos processos de criação de novos saberes ${ }^{6}$, de educação da sociedade.

Essa nova dinâmica acaba por ser destinada somente a um grupo social privilegiado, que reforça e aumenta, com uma velocidade ímpar, a desigualdade social, ou pode ser a grande oportunidade de inserção social dos grupos excluídos, resgatando, a estes, a condição de cidadania.

À medida que o acesso às tecnologias da informação e comunicação redesenha os processos de relação em uma sociedade e redesenha o exercício da cidadania, ao Estado-nação cabe a responsabilidade de assegurar a inclusão digital e, consequentemente, a inclusão social, por meio de políticas públicas. Estas nada mais são do que as chamadas ações afirmativas ${ }^{7}$, as quais buscam promover a igualdade, o equilíbrio de oportunidades entre diversos grupos sociais, no caso, mediado pelas Tecnologias da Informação e Comunicação. Entre as políticas públicas de inclusão digital, encontram-se,

\footnotetext{
${ }^{3}$ Canotilho defende a superação da concepção moderna de Estado-nação. CANOTILHO, José Joaquim Gomes. Estado de Direito. Cadernos Democráticos, n 7 , Fundação Mário Soares, Lisboa: Gradiva, 1998, p. 44.

${ }_{5}^{4}$ OST, François. O Tempo do Direito. Porto Alegre: Editor Instituto Piaget, 1999, p. 15

5 O Brasil encontra-se hoje diante dos grandes desafios que o desenvolvimento das telecomunicações trouxe para o século XXI. Este século será, no futuro, conhecido como o século das infovias, assim como o século $\mathrm{XIX}$ foi o das ferrovias e o século $\mathrm{XX}$ foi 0 das rodovias e aerovias. Todas essas infra-estruturas exigiram imensos investimentos e foram as grandes alavancas do progresso das nações. Com as infovias não será diferente. Mas há aspectos em que a sua construção tem características próprias: a velocidade e a urgência com as quais elas precisam ser implantadas são determinantes para alcançar metas de inclusão digital e da inclusão social daí decorrente. (NETTO, Alexandre Annenberg. Infovias. In: CGI.br (Comitê Gestor da Internet no Brasil). Pesquisa sobre o Uso das Tecnologias da Informação e da Comunicação 2008. São Paulo, 2009, p. 53-56). As infovias são, em outras palavras, estradas eletrônicas onde pode transitar todo tipo de informação, na forma de texto, som ou imagem, entre um ponto gerador e diferentes pontos receptores. Elas são formadas por plataformas eletrônicas, destacando-se como principais o telefone, a televisão, a Internet, os servidores, as bibliotecas multimídia e as salas de videoconferência.

${ }^{6}$ MORIN, Edgar. Jornadas Temáticas (1998: Paris, França: 1998). A Religação dos Saberes: o desafio do século XXI / idealizadas e dirigidas por Edgar Morin, tradução e notas, Flávia Nascimento. 2. ed., Rio de Janeiro: Bertrand Brasil, 2002, p. 489 e ss.

${ }^{7}$ As ações afirmativas são medidas especiais e temporárias, tomadas ou determinadas pelo Estado, espontânea ou compulsoriamente, com o objetivo de eliminar desigualdades historicamente acumuladas, garantindo a igualdade de oportunidades e tratamento, bem como de compensar perdas provocadas pela discriminação e marginalização, decorrentes de motivos raciais, étnicos, religiosos, de gênero e outros. Portanto, as ações afirmativas visam combater os efeitos acumulados em virtude das discriminações ocorridas no passado. (LIMA JÚNIOR, Jayme Benvenuto. Os Direitos Humanos Econômicos, Sociais e Culturais. Rio de Janeiro: Renovar, 2001, p. 138).
} 
amplamente difundidos em vários países, os telecentros, isto é, espaços físicos nos quais estão alocados computadores conectados à internet para uso da comunidade, de maneira geral em caráter de gratuidade. As formas de gestão desses espaços são bastante diversificadas, mas podem apresentar como aspecto em comum a indicação da necessidade de promover uma educação orientada para o desenvolvimento da cidadania.

Uma vez que o desenvolvimento tecnológico, principalmente, por meio das tecnologias de informação e comunicação, está modificando as relações sociais, é de basilar importância a existência de políticas públicas e ações afirmativas diversas que promovam o resgate dos excluídos digitais, possibilitando-Ihes participar de forma efetiva da sociedade, atualmente conhecida como: Sociedade do Conhecimento, mas também conhecida como Sociedade da Informação.

Diversos autores já tentaram definir a expressão "Sociedade da Informação". Segundo Gouveia ${ }^{8}$, o conceito de Sociedade da Informação é originário das pesquisas de Alain Touraine e Daniel Bell ${ }^{9}$ do final de década de sessenta sobre a influência dos avanços tecnológicos nas relações de poder, que identificaram a informação como elemento central da sociedade contemporânea.

Gaio e Gouveia ${ }^{10}$ definem Sociedade da Informação como a "sociedade que recorre predominantemente às tecnologias da informação e comunicação para troca de informação em formato digital, suportando a interação entre indivíduos e entre estes e instituições, recorrendo a práticas e métodos em construção permanente". Por sua vez, Kumar $^{11}$ a definiu como uma nova forma de organização e de produção da sociedade em escala mundial, baseada no conhecimento, na educação e no desenvolvimento científico e tecnológico.

Embora na sua acepção original o termo "inclusão digital" tenha sido utilizado somente para distinguir situações de desigualdade no acesso à internet, recentemente a expressão vem sendo melhor lapidada, tendo sua compreensão desenvolvida.

Atualmente, a expressão exclusão digital é empregada para indicar "falhas no provimento pelos governos de acesso universal a serviços de informação e comunicação, indistintamente a todos os cidadãos" ${ }^{\prime 2}$.

8 "Sociedade da Informação - Notas de Contribuição para uma Definição Operacional", GOUVEIA, Luis Manuel Borges. nov. 2004, Disponível em: Im@ufp.pt,http://ufp.pt/ Imbg.

${ }^{9}$ Alain Touraine e Daniel Bell foram provavelmente os primeiros sociólogos a teorizar sobre a Sociedade Pós-Industrial, momento em que o conhecimento se tornou a principal força econômica de produção.

10 GOUVEIA, Luis Manuel Borges; GAIO, Sofia. "Sociedade da Informação: balanço e oportunidades". Edições Universidade Fernando Pessoa, 2004.

${ }^{11}$ KUMAR, Krishan. "Da Sociedade Pós-industrial à Pós-moderna: novas teorias sobre o mundo contemporâneo". Rio de Janeiro: Jorge Zahar, 1997.

${ }^{12}$ MEDEIROS, Paulo Henrique Ramos. "Governo Eletrônico no Brasil: aspectos institucionais e reflexos na governança", 2004. 
Por sua vez, para o Grupo Telefônica, exclusão digital é o termo "utilizado para designar as desigualdades existentes entre as diferentes classes sociais no que se refere às possibilidades de acesso à Sociedade da Informação"13.

Inclusão digital é o "processo de alfabetização tecnológica e acesso a recursos tecnológicos, no qual estão inclusas as iniciativas para a divulgação da Sociedade da Informação entre as classes menos favorecidas, impulsionadas tanto pelo governo como por iniciativas de caráter não governamental"14.

A inclusão digital é um processo constante, onde cada vez que uma nova tecnologia surge há a necessidade de ampliar o público que tem acesso a ela.

\section{TELETRABALHO COMO NOVA FORMA DE PRESTAR SERVIÇOS NA ERA DAS NOVAS TECNOLOGIAS}

A correlação entre o preparo técnico e a capacidade de se inserir no mercado de trabalho depende do potencial do indivíduo que busca fazer parte da malha social.

O número de postos de trabalho no segmento das Tecnologias da Informação e Comunicação sofreu forte incremento a partir da primeira década do século XXI com a criação de novos empregos, em especial no setor privado.

As tecnologias da informação e comunicação tornaram-se imprescindível ferramenta de trabalho, possibilitando uma série de benefícios aptos a agilizar a transmissão de informações, aumentar a produção e reduzir gastos operacionais. Todas essas transformações foram inseridas nas relações de trabalho que não mais apresentam as características de tempo, espaço e organização que antes apresentavam, onde a energia e o esforço físico do trabalho humano eram os responsáveis pelo desenvolvimento da economia.

Do atual trabalhador são exigidos conhecimentos cada vez mais complexos, habilidades diferenciadas e maior qualificação profissional. Assim, a realidade revela uma mudança de paradigma manifestada em um novo ambiente de trabalho descentralizado dos centros de produção e centralizado no conhecimento e na informação. Até mesmo as tradicionais formas de prestação de serviços aos poucos vão cedendo espaço a novas relações contratuais que nem mesmo exigem a presença física do trabalhador, como por exemplo, o Teletrabalho.

${ }^{13}$ Grupo Telefônica, "A Sociedade da Informação - Presente e Perspectivas", p. 35, ano 2002. apud NAZARENO, Cláudio (et. al.). Tecnologias da Informação e Sociedade: o panorama brasileiro. Brasília: Câmara dos Deputados, Coordenação de Publicações, 2006, 187p (p. 14).

${ }^{14}$ Grupo Telefônica, "A Sociedade da Informação - Presente e Perspectivas", p. 35, ano 2002. apud NAZARENO, Cláudio (et. al.). Tecnologias da informação e Sociedade: o panorama brasileiro. Brasília: Câmara dos Deputados, Coordenação de Publicações, 2006, 187p (p. 14). 
O teletrabalho aparece como uma nova modalidade de prestação de serviços, sem cobertura legal específica e até o momento sua definição não responde a critérios jurídicos, mas sim, a considerações práticas.

Os conceitos sobre teletrabalho são variados se encontram em processo de formação, não existindo um consenso por parte dos estudiosos, na medida em que surge num cenário influenciado por institutos como: a globalização e a flexibilização.

A necessidade de reformulação do contrato de trabalho tradicional em novas modalidades laborais representa a tentativa progressiva de gerar novos empregos, manter os existentes e, principalmente, regularizar a situação dos trabalhadores que se encontram excluídos.

Nesse sentido, o prefixo tele está sendo entendido como telecomunicações, mas quer dizer distância ${ }^{15}$. Todavia, com frequência, o teletrabalho é comparado com o trabalho em domicílio, o que não incorre na mesma espécie de relação de trabalho, sendo que tanto o teletrabalho quanto o trabalho em domicílio são espécies de trabalho a distância, conforme alude Pinho Pedreira. ${ }^{16}$

Alvin Tofller $^{17}$ corrobora no sentido de que a noção de teletrabalho aparece primeiramente associada ao trabalho a domicílio, o qual, quer sob o ponto de vista social, econômico ou jurídico, principalmente neste, significa "trabalho executado na habitação do empregado ou oficina da família, por conta do empregador que o remunere" (Decreto-lei n 399, de 30 de abril de 1938).

Frederico Silveira e Silva ${ }^{18}$ explica que o "teletrabalho é uma espécie de trabalho a distância. Um equívoco freqüente é compará-lo ao trabalho em domicílio, visto que o teletrabalho não se limita ao domicílio", podendo ser prestado dentro da própria empresa, abstraindo o contato direto do empregado com o empregador, como também em centros intermediários de trabalho descentralizados da empresa e dotados de instalações e equipamentos próprios para o desenvolvimento de tarefas, no caso, por meio do uso das tecnologias da informação e comunicação. ${ }^{19}$

Portanto, na hora de conceituar, cabe observar a relação entre a utilização ou não de tecnologias de informação e comunicação, principalmente para não confundir teletrabalho com trabalho em domicílio, segundo Alice Monteiro de Barros ${ }^{20}$.

15 JARDIM, Carla Carrara da Silva. O Teletrabalho e suas Atuais Modalidades. São Paulo: LTr, 2003.

${ }^{16}$ PEDREIRA, José Pinho. O Teletrabalho. Revista LTr, São Paulo, v. 64, nº 5, maio 2000.

${ }^{17}$ TOFLLER, Alvin. A Terceira Onda. 16. ed., Rio de Janeiro: Record, [s.d]. p. 200-205.

${ }^{18}$ SILVA, Frederico Silveira e. O Teletrabalho como Novo Meio de Laborar e sua Compatibilidade com o Ordenamento Jurídico. Revista CEJ, Brasília DF, n² 27, 2004, p. 102-109.

19 PINTO, José Augusto Rodrigues; PAMPLONA FILHO, Rodolfo. Repertório de Conceitos Trabalhistas: Direito Individual. v. 1, São Paulo: LTr, 2000.

${ }^{20}$ BARROS, Alice Monteiro de. Curso de Direito do Trabalho. 2. ed., São Paulo: LTr, 2006, p. 304. 
Jack Niles, inventor do vocábulo "teletrabalho", afirma que ao instituto em exame se atribui qualquer atividade profissional que se realiza fora do lugar tradicional de trabalho, utilizando alguma das técnicas de telecomunicações ${ }^{21}$, o definiu como: "a possibilidade de enviar o trabalho aos trabalhadores, em vez de levar estes ao trabalho."22

Para Pinho Pedreira, o teletrabalho corresponde à modalidade de trabalho atípico resultante do conceito flexível de lugar de trabalho, aonde se observa uma erosão do modelo tradicional e o abandono do presenteísmo. ${ }^{23}$

Denise Pires Fincato ${ }^{24}$, por sua vez, afirma que "o teletrabalho constitui-se em modalidade surgida dessa revolução informacional, que mescla os avanços tecnológicos (principalmente informáticos) e comunicacionais."

Nesta concepção, a inovação tecnológica subverte a relação de trabalho clássica, sendo responsável por novos tipos de atividade descentralizada, que reúnem informação e comunicação.

Verifica-se que nesta nova forma de prestar serviços o prestador necessita, além dos conhecimentos típicos de sua função, agregar meios que possibilitem executar os serviços. Estes meios podem ser alcançados pelo empregador ou tomador dos serviços, como disponibilizado agente político, que auxilia a inclusão profissional, e viabiliza a inclusão social.

3 FORMAÇÃO PROFISSIONAL E EDUCAÇÃO FACE AO USO DAS TECNOLOGIAS DA INFORMAÇÃO E COMUNICAÇÃO

Conforme já mencionado, as tecnologias da informação e comunicação convergem para o desenvolvimento do setor econômico, todavia, são exigidos do atual trabalhador conhecimentos cada vez mais complexos, habilidades diferenciadas e maior qualificação profissional. Registre-se que esta qualificação é permanente, requerendo do novo profissional uma capacidade de mutação e adaptabilidade ao meio criado pela Sociedade da Informação jamais antes experimentado na história da humanidade.

O economista e jornalista Gilson Schwartz ${ }^{25}$ entende que a exclusão digital não seria, pura e simplesmente, a pessoa ficar sem computador ou telefone celular, por exemplo, mas, sim, continuar incapaz de pensar, de criar e de organizar novas formas, mais justas e dinâmicas, de produção e de distribuição de riqueza simbólica e material.

\footnotetext{
${ }^{21}$ BRANDOLINO, Enrique Ricardo. Tele Trabalho. In: VARGAS, Luiz Alberto de; FRAGA, Ricardo Carvalho (Coord.). Avanços e Possibilidades do Direito do Trabalho. São Paulo: LTr, 2005.

${ }^{22}$ NILES, Jack; apud PINTO, José Augusto Rodrigues. Teletrabalho. Revista de Doutrina e Jurisprudência do TRT da 16a Região, São Luis, v. 13, nº 1, jan./dez. 1994.

${ }^{23}$ PEDREIRA, José Pinho. O Teletrabalho. Revista LTr, São Paulo, v. 64, nº 5, maio 2000

${ }^{24}$ FINCATO, Denise Pires. Teletrabalho: uma análise juslaboral. Revista Justiça do Trabalho, Porto Alegre: HS Editora, $n^{\circ} 236$, ago. 2003, p. 41.

${ }^{25}$ SCHWARTZ, Gilson. "Exclusão Digital entra na Agenda Econômica Mundial". São Paulo: Folha de S. Paulo, 2000.
} 
Ao falarmos em riqueza simbólica e pobreza do conhecimento precisamos lembrar dos instrumentos cognitivos de obtenção do conhecimento, sem os quais este seria impossível. Falar em alfabetização digital diante do analfabetismo funcional não seria algo um tanto quanto equivocado. A inclusão digital não pode se restringir à escola e ao ensino formal, mas deve abrir outros espaços de acesso ao conhecimento, e, por sua vez, às tecnologias da informação e comunicação.

É importante salientar que a maioria das habilitações de uma pessoa, obtidas no trabalho ou na escola, mesmo em nível superior, atualmente, acabam por ser rapidamente superadas, eis que a renovação veloz e constante do conhecimento é um dos principais elementos que caracterizam a chamada Era da Informação ${ }^{26}$.

Assim, conforme dito anteriormente, a natureza do trabalho na sociedade atual também vai se alterando. Transacionar conhecimento passa a ser uma das principais habilidades requeridas dos trabalhadores pelos empregadores da nova economia e pela grande migração de empresas tradicionais para a economia em rede, assim como nas relações onde há a prestação de serviço.

A educação que cultiva a ideia do saber consolidado deve ser substituída, mas não esquecida, pela que ensina e prepara a pessoa para o aprendizado permanente. A política educacional deve ser formulada para absorver e utilizar as tecnologias intelectuais que amplificaram a inteligência humana e suas funções cognitivas. A memória foi ampliada pelos bancos de dados, pelos documentos em hipermídia e pelos arquivos digitais. A imaginação teve nas tecnologias de simulação um avanço considerável. A pesquisa dá saltos com o saber compartilhado entre estudiosos e pesquisadores. ${ }^{27}$

A polêmica reside na questão que envolve o potencial de inteligência individual e coletiva da sociedade. O ensino deve ponderar essa conjuntura e levar para a comunidade a noção de um saber que se constrói. O modelo de uma formação tecnicista e mecanicista, típica da fase taylorista-fordista, centrada na linearidade e na escala piramidal está absolutamente superado. A ideia de ensino aberto ao jovem e à sua comunidade deve ser incorporada a todo e qualquer programa de inclusão digital e alfabetização tecnológica. A expansão constante requer ir além dos padrões pré-concebidos e construir novos modelos. Os modelos e as abstrações estão relacionados com a utilidade e a finalidade, as quais se vinculam, em um determinado local e em uma determinada época; mas a construção de novos modelos é uma necessidade constante. Para usar uma linguagem da biologia, pois ocorre uma seleção natural dos modelos e só os mais aptos, também na cultura

${ }^{26}$ CASTELLS, Manuel. A Sociedade em Rede (A Era da Informação: economia, sociedade e cultura, v. 1). Tradução de Roneide Venâncio Majer, atualização para 6. ed., Jussara Simões. São Paulo: Paz e Terra, 1999.

27 SILVEIRA, Sérgio Amadeu da. "O Duplo combate à Pobreza do Conhecimento e a Necessidade da Alfabetização Tecnológica". In Exclusão Digital: a miséria na era da informação. São Paulo: Editora Fundação Perseu Abramo, 2001, p. 28. 
jurídica, permanecem, e, quando não se adaptam ao momento histórico e cultural, devem ser criados outros novos. Não perceber este momento de alteração e querer repetir modelos desconectados com o mundo atual é o problema a ser resolvido. Zimerman destaca a importância dos modelos na psicanálise e demonstra também com um exemplo elucidativo a sua transitoriedade: "Assim, o modelo que a mim ocorre para conceber essa última definição é o dos andaimes de uma obra em construção: eles são úteis e indispensáveis até que a construção se complete e então se os dispense" ${ }^{28}$.

Pensamento semelhante é advogado por Castanheira Neves, onde a ideia de um modelo metódico de realização do direito a partir da dialética entre as dimensões do sistema e do problema, a partir da organização dos contornos estruturais do que seja "questão de fato-questão de direito" e a partir da certeza da impossibilidade de que cada uma delas não pode ser individualmente considerada. A referência lançada pelo Autor parte da compreensão do "caso jurídico" percebido como concreto no sentido problemático e verifica o problema jurídico numa situação histórico-social como obstáculo, uma exigência de cumprimento em contraste com uma situação real que resiste. Segundo o Autor, em virtude da alteração de seus elementos, os problemas acabam por situar-se de modo diverso, e por esta razão torna-se necessária a automização do pensamento problemático perante o anterior, já que não é possível deduzir deste a posição de problema novo. Para o Autor, a juridicidade assemelha-se ao modelo axiológiconormativo que se constitui na vida histórica de uma determinada comunidade e se desdobra em três dimensões: mundano-social, antropológico-existencial e ética. $^{29}$ O conhecimento prévio do saber jurídico, compreendendo-o as normas positivas, a jurisprudência e a doutrina, não dispensa uma autônoma referência ao problema a ser decidido, em uma consciência do não saber fundamentante. Castanheira Neves concluiu que a indagação do caso concreto faz emergir dele um sentido problemático que só é possível esclarecer a partir do projeto axiológico que é escolhido. Elabora-se uma contínua integração dos princípios conforme as intenções axiológicoculturais desnudadas com as decisões dos casos concretos. A determinação da validade de uma situação concreta com referência às intenções axiológiconormativas transcende essa mesma situação, objetivando-se. O próprio sentido da situação problemática analisada é que faz nascer os limites de relevância da situação. A individualidade objetivada é a identificação de uma relevância, e o caso jurídico concreto consiste na unidade jurídico-material entre a situação e o problema. ${ }^{30}$

\footnotetext{
28 ZIMERMAN, D. E. Bion: da Teoria à Prática. Uma Leitura Didática. Porto Alegre: Artes Médicas, 1995, p. 43. Também se poderia pensar nos modelos para a feitura de uma escultura, ou um quadro enquanto o pintor faz nascer a obra.

${ }^{29}$ CASTANHEIRA NEVES, Antonio. Metodologia Jurídica: problemas fundamentais. Coimbra: Coimbra Editora, 1993, p. 154 e ss.

${ }^{30} \mathrm{O}$ problema é compreendido aqui como a pergunta. Significativa a reflexão que desenvolve Emmanuel Carneiro Leão no que toca a toda pergunta: "No pensamento, a fala nunca é primeiro.
} 
A conjugação de uma intenção normativa geral ou de validade com uma situação concreta é a pré-síntese de um sentido concreto de intenção jurídica, ou o próprio problema jurídico. Dissociando metodologicamente os momentos de análise do caso jurídico, aponta o autor para a questão de fato e para a questão de direito. A questão de fato fixa a relevância da situação histórico-concreta e a demonstração dos elementos específicos dessa relevância e de seus efeitos. A questão de fato não deixa de ser uma questão de direito que diz com a identificação e seleção das circunstâncias do problema jurídico concreto. ${ }^{31}$

Produto característico da cultura nacional e com uma visão em perspectiva, no que toca à educação, demarca Paulo Freire o desafio do conhecer para transformar:

A educação é um ato de amor, por isso, um ato de coragem. Não pode temer o debate. A análise da realidade. Não pode fugir à discussão criadora, sob pena de ser uma farsa. Como aprender a discutir e a debater com uma educação que impõe? Ditamos idéias. Não trocamos idéias. Discursamos aulas. Não debatemos ou discutimos temas. Trabalhamos sobre o educando. Não trabalhamos com ele. Impomos-lhe uma ordem a que ele não adere, mas se acomoda. Não lhe propiciamos meios para o pensar autêntico, porque recebendo as fórmulas que Ihe damos, simplesmente as guarda. Não as incorpora porque a incorporação é o resultado da busca de algo que exige, de quem o tenta, esforço de recriação e de procura. Exige reinvenção. ${ }^{32}$

O processo de educação consiste também em saber distinguir a diferença existente entre as palavras educar e instruir, uma distinção que não pode ser esquecida ou de maneira deliberada confundida. Dulce Mara Critelli, relembrando o pensamento de Martin Heidegger, refere:

Instrução e educação são fenômenos que nada têm a ver um com o outro. Instruir é treinar, condicionar, informar, adestrar. Educar, por sua vez, vem do latim ex-ducere, que quer dizer "conduzir ou arrancar para fora", subentendemos, de uma condição de existência para outra.

O pensamento nunca fala de modo próprio. Sempre responde por já ter escutado. Toda pergunta ou questão do pensamento torna-se radical por já ser sempre resposta. Só se consegue dizer a palavra essencial na escuta do sentido, a essência de escuta do sentido. Obediência é uma audiência atenta do sentido. Por lhe dirigir continuamente a essência da palavra, o tempo, enquanto pronome do ser, está sempre dizendo a palavra crucial, mas que o pensamento só consegue repetir numa variedade infinita de palavras, de gestos, de sentidos, de ações". Ver neste sentido Emmanuel Carneiro Leão na apresentação feita a obra "Ser e Tempo" de Martin Heidegger, para o público leitor brasileiro. 10. ed., Tradução de Márcia de Sá Cavalcante, Petrópolis: Vozes, 2001, p. 15.

${ }^{31}$ CASTANHEIRA NEVES, Antonio. Metodologia Jurídica: problemas fundamentais. Coimbra: Coimbra Editora, 1993, p. 154 e ss.

${ }^{32}$ FREIRE, Paulo. Educação como Prática da Liberdade. 23. ed., Rio de Janeiro: Paz e Terra, 1999, p. 42. 
Se, em verdade, substituímos a educação pela instrução, é à segunda e não à primeira que nos temos remetido em nossas discussões; é com a instrução que nos temos preocupado. Tal situação acaba de dirimir, de uma vez por todas, a questão educacional que imaginávamos refletir. Além disso, ela nos vem denunciar que nossa contemporaneidade não tem espaço para a educação, mas só para a instrução. Sendo a instrução, desta feita, o fenômeno a ser pensado, aquilo que se evidenciava logo ao primeiro lançar de olhos no fenômeno educação a ser saber, o sermos-uns-com-os-outros - já não mais se mostra e, de uma maneira muito particular, nem tem mais por que se presentificar. Aquilo que na instrução se manifesta como seu constitutivo básico são os processos, os conteúdos, instrumentos, recursos, objetos e objetivos da instrução. As relações homem-homem, neste âmbito, não são mais a "oportunidade", mas os "subsídios" da concretização de tal tarefa. ${ }^{33}$

Um método de ensinar que promova o incentivo a aprendizagem individual e coletiva, em rede e pela rede; este deve ser o espírito da alfabetização tecnológica. Educar não pode ser entendido como aquilo que se pratica dentro dos muros escolares. Educar é cada vez mais mergulhar na fronteira virtual. ${ }^{34}$

A recomposição dos vínculos afetivos está para a solução dos conflitos e das angústias internas e pessoais, assim como a recomposição dos vínculos com os institutos jurídicos do passado está para a solução dos conflitos e agruras sociais. Repensar e reconstruir necessita conhecer a si muito bem, assim como o passado dos nossos institutos e as abstrações por nós construídas para, a partir delas, reconstruir um direito sob novos paradigmas, sob a moldura flexível do mundo que agora se refaz.

4 CONTROVÉRSIAS SOBRE A NECESSIDADE DE UNIVERSALIZAÇÃO DAS TECNOLOGIAS DA INFORMAÇÃO E COMUNICAÇÃO

$O$ agravamento do quadro de desigualdades no acesso às tecnologias digitais tem acarretado debates acalorados entre especialistas a respeito da necessidade da adoção de políticas públicas orientadas para a infoinclusão como instrumento de desenvolvimento dos grupos sociais menos favorecidos economicamente.

Castells $\mathrm{s}^{35}$ entende que não há mais como tentar implantar modelos de desenvolvimento alternativo, com menores exigências tecnológicas, ganhos de produtividade reduzidos e que assegurem a preservação integral da identidade cultural dos povos. A velocidade do avanço na Internet não deixou

\footnotetext{
${ }^{33}$ Ver comentário de Dulce Mara Critelli. In HEIDEGGER, Martin. Todos Nós ... ninguém Um Enfoque Fenomenológico Social. São Paulo: Moraes, 1981, p. 63-64.

${ }^{34}$ SILVEIRA, Sérgio Amadeu da. "O Duplo Combate à Pobreza do Conhecimento e a Necessidade da Alfabetização Tecnológica". In Exclusão Digital: a miséria na era da informação. São Paulo: Editora Fundação Perseu Abramo, 2001, p. 28.

${ }^{35}$ CASTELLS, Manuel. A Galáxia da Internet: reflexões sobre Internet, Negócios e Sociedade. Lisboa: Fundação Calouste Gulbenkian, 2004, 325p.
} 
margem para escolha, limitando as trajetórias de desenvolvimento de modo a privilegiar apenas aqueles povos que optarem pela educação digital de sua população. Por esse motivo, a se perpetuarem as desigualdades digitais, se delineia uma crise a partir da marginalização dos países que não optarem ou não tiverem a oportunidade de optar - pela imersão na Era da Informação.

Esse sistema tecnológico, em que estamos totalmente imersos na aurora do século XXI, surgiu nos anos 70. Devido à importância de contextos históricos específicos das trajetórias tecnológicas e do modo particular de interação entre a tecnologia e a sociedade, convém recordarmos algumas datas associadas a descobertas básicas nas tecnologias da informação. Todas têm algo de essencial em comum: embora baseadas principalmente nos conhecimentos já existentes e desenvolvidas como uma extensão das tecnologias mais importantes, essas tecnologias representaram um salto qualitativo na difusão maciça da tecnologia em aplicações comerciais e civis, devida a sua acessibilidade e custo cada vez menor, com qualidade cada vez maior. ${ }^{36}$

$\mathrm{Na}$ atualidade, ambicionar o desenvolvimento econômico, cultural e social sem contar com o acesso de qualidade à Internet e às Tecnologias da Informação e Comunicação equivale ao que seria uma suposta tentativa de industrialização no século XIX sem contar com as fontes de energia elétrica. Segundo essa concepção, não há mais como se cogitar a ideia de assegurar a educação, saúde, segurança e etc. sem se pensar em desenvolvimento tecnológico.

No entanto, a tese de que a inclusão digital consiste em condição indispensável para que os cidadãos tenham representatividade na sociedade moderna passou a ser questionada. Do lado diretamente oposto a essa teoria, há aqueles que defendem que a globalização e a inserção da pessoa na Era do Conhecimento apenas têm contribuído para a massificação dos valores culturais advindos dos países economicamente dominantes e para a redução das identidades culturais de cada povo. ${ }^{37} \mathrm{O}$ quadro tende a perpetuar as desigualdades cultural e social, pois submete os diferentes estratos sociais a distintos ambientes tecnológicos. "A diversidade é desafiante, mas alguns, entre os quais Castells, ainda acreditam que é preciso refletir sobre os contextos novos em que se desenrola a vida social para compreender os mecanismos de mudanças e, partindo dessas situações buscar um novo quadro teórico para explicá-los. ${ }^{38}$ Castells mostrou o efeito das transformações

\footnotetext{
${ }^{36}$ CASTELLS, Manuel. A Sociedade em Rede (A Era da Informação: economia, sociedade e cultura, v. 1). Tradução de Roneide Venâncio Majer, atualização para 6. ed., Jussara Simões. São Paulo: Paz e Terra, 1999, p. 91.

${ }^{37}$ CASTELLS, Manuel. A Galáxia da Internet: reflexões sobre Internet, Negócios e Sociedade. Lisboa: Fundação Calouste Gulbenkian, 2004, 325p (p. 208-213).

${ }_{38}$ Prefácio escrito por Ruth Correa Leite Cardoso ao livro A Era da Informação: Economia, Sociedade e Cultura - O Poder da Identidade, obra de Manuel Castells, Volume 2, 5. ed., Editora Paz e Terra.
} 
tecnológicas especialmente na era da comunicação e o impacto da informatização sobre as culturas de todo o globo.

A partir dos pressupostos acima mencionados é justificável o temor da perda de identidade e o desrespeito às diferenças regionais, culturais $\mathrm{e}$ ambientais.

\section{A SOCIEDADE DA INFORMAÇÃO A SERVIÇO DA INCLUSÃO} SOCIAL

As tecnologias da informação e comunicação vieram para ficar e não podem ser comparadas com instrumentos tais como: o lápis, a máquina de escrever ou o giz. Frente às suas possibilidades de interação e sua dinâmica em construir e desconstruir - com uma velocidade não palpável - o conhecimento, devemos percebê-las, mais do que um fenômeno tecnológico, como um fenômeno econômico, cultural, político e social.

A possibilidade de essas novas tecnologias aumentarem, em grande escala, o fosso da desigualdade social existente nos dias de hoje é real, pois enquanto aumenta a organização da economia e do trabalho mediada pelo computador e pela comunicação em rede, por exemplo, também aumenta o número de excluídos digitais.

A inclusão digital está intimamente ligada a inclusão social, pelo fato de haver uma democratização do acesso à informação disponibilizando tecnologia à população. Cabe ressaltar que o principal objetivo não é disponibilizar a tecnologia em si, mas sim a integração perfeita do indivíduo excluído digitalmente na sociedade.

Quando se terá um resultado para reverter a situação do analfabetismo digital? Resposta objetiva, mas não simples de se perfectibilizar: a exclusão digital acabará quando o "usuário aprende que o computador é um meio de acesso à educação, ao trabalho, ao contato e troca com a sua comunidade, ao pensamento crítico e ao exercício pleno de sua cidadania".

O desafio reside em propiciar o uso das novas tecnologias para a grande massa da população, por isso as políticas públicas, as organizações não-governamentais e a sociedade civil criaram uma nova forma de sediar um conjunto de novas tecnologias para um público despossuído de recursos econômicos para adquirí-las ou utilizá-las, mas detentor de informação e conhecimento para usufruí-las. Por isso, precisando, com urgência, da promoção de ações para combatê-lo, ações transformadoras que busquem solucionar essa exclusão social.

Os espaços de inclusão digital - tenham a denominação que tiverem podem ser considerados como ações imprescindíveis em prol da diminuição desse distanciamento entre os que têm acesso às tecnologias, ainda minoria, e os que não têm acesso às tecnologias, a grande massa. Mas, somente Ihes será atribuído o papel de ação transformadora se possuírem uma educação emancipatória. Uma educação baseada em teorias, propostas 
pedagógicas e experiências de aprendizagem possíveis de se realizar de forma solidária e participativa. Educar, hoje, é engajamento social, é criar esperanças, é aumentar a auto-estima, é aumentar os níveis de expectativa, é ensinar a inovar, é incentivar a capacidade de tomar iniciativas.

A luta pelo acesso ao ciberespaço, como resgate à cidadania, justifica-se no momento em que o acesso aos outros direitos humanos passa pelo acesso do cidadão à informação e ao conhecimento. A participação no ciberespaço, em todas as dimensões - econômicas, políticas, culturais e sociais -, é passagem obrigatória para o acesso ao conhecimento e, consequentemente, ao meio social. ${ }^{39}$

A inclusão digital passa a ser uma das trilhas pela qual os indivíduos deverão caminhar, com o propósito de se incluírem socialmente, jornada que Ihes promoverá o exercício da cidadania.

A desarticulação entre o "social" e o "individual", operada pela racionalidade técnica, modifica também o conceito tradicional de "massa", introduzindo uma variante que é a sua atomização e desarticulação em singularidades individuais que, modeladas por produtos de massa, consumos de massa, informações de massa, tornaram obsoleto o conceito de massa como concentração de muitos, e atual o de massificação como qualidade de milhões de indivíduos, cada um dos quais produz, consome e recebe as mesmas coisas de todos, mas de modo solitário. Assim, é atribuída a cada um a própria massificação, mas com a ilusão da privacidade e o aparente reconhecimento da própria individualidade, de modo que ninguém esteja mais em condição de perceber um "externo" em relação a um "interno", porque o que cada um encontra em público é exatamente igual àquilo de que dispõe privadamente. Nasce daí o processo de desinvidualização que está na base das condutas de massa típicas das sociedades ratificadoras e conformistas. Para a ratificação social contribuem de modo exponencial os meios de comunicação, que a técnica potencializou modificando o nosso modo de fazer experiência: não mais em contato com o mundo, mas com a representação midiática do mundo, que torna próximo o longínquo, presente o ausente, disponível aquilo, de outra forma, estaria indisponível. Libertando-nos da experiência direta e colocando-nos em relação, não com os eventos, mas com a sua representação, os meios de comunicação não precisam falsificar ou esconder a realidade, porque justamente a própria informação codifica, e o efeito de código torna-se não só critério interpretativo da realidade, mas também modelo indutor dos nossos juízos, que, por sua vez, geram comportamentos no mundo real conforme ao que foi aprendido e a partir do modelo indutor. ${ }^{40}$

39 LÉVY, Pierre. A Conexão Planetária: o mercado, o ciberespaço, a consciência. (Trad.) HOMEM, Maria Lúcia; ENTLER, Ronaldo. São Paulo: Ed. 34, 2001, p. 57.

${ }^{40}$ GALIMBERTI, Umberto. Psiche e Techne: o homem na idade da técnica. Tradução: José Maria de Almeida. São Paulo: Paulus, 2006, p. 20-21. 
O século XXI apresenta algumas mudanças e tendências que, pelo uso das novas tecnologias, alteram estruturalmente a forma de conviver, de se comunicar, de ensinar, de aprender e de trabalhar.

Para o processo de educação, passa a ser plenamente factível estudar à distância, mediado pelas novas tecnologias e por professores que não estão no espaço geográfico local. O processo produtivo, por sua vez, torna-se, cada vez mais, usuário das novas tecnologias, em especial por meio do teletrabalho.

Para ser cidadão, no mundo contemporâneo, é necessário fazer parte, usufruir deste conjunto de possibilidades as quais as mídias digitais proporciona.

Ao planejar e instaurar espaços educativos, privilegiando a inclusão digital em prol de uma inclusão social, é preciso não perder de vista que está em questão algo maior do que garantir uma condição de trabalho aos indivíduos associados a este espaço. Está em discussão uma nova forma de comunicação, preponderantemente, instalada no mundo globalizado.

Portanto, o acesso às novas tecnologias deve permitir mais do que a manutenção do sistema produtivo existente, o qual visa, primordialmente, a qualificação de uma sociedade para suprir as demandas de mercado de trabalho.

Precisa, também, promover a formação de cidadãos, cidadãos não mais locais, mas cidadãos do mundo, propiciando, por meio de suas interações, as transformações sociais necessárias na busca de uma sociedade mais plena.

Do Estado, a sociedade espera que este assuma a responsabilidade de participar do desenvolvimento deste novo cidadão, oportunizando-lhe mais do que o acesso digital, a qualidade deste acesso.

Com isto, o presente artigo exemplifica como uma forma de política pública de inclusão digital, a parceria entre o Poder Público e entidades civis ou não-governamentais para implementação de telecentros.

Procurando reduzir tal quadro de exclusão, surgiram iniciativas que buscam democratizar o acesso à essas tecnologias. No ano de 1999, com o lançamento da política de informação com o Programa da Sociedade da Informação - Livro Verde ${ }^{41}$, pelo Ministério da Ciência e Tecnologia do Governo Federal, tentou-se criar uma política que regulasse e incentivasse as iniciativas nessa linha. Uma iniciativa anterior ao lançamento desse Programa, foi a criação, a partir de 1996, em Santa Catarina, do primeiro telecentro no Brasil.

\footnotetext{
${ }^{41}$ Documento resultante do Programa Sociedade da Informação (Soclnfo) instituído por Decreto Presidencial ( $n^{\circ}$ 3294) em 1999, com o objetivo de integrar, coordenar e fomentar ações para utilização de tecnologias de informação e comunicação de forma a contribuir para a inclusão social de todos os brasileiros na nova sociedade.
} 

é um

centro de atendimento coletivo que oferece serviços, em regime de parcerias, aos diversos segmentos da sociedade da área urbana e da área rural, utilizando facilidades de telecomunicações e de informática e atuando como agente de desenvolvimento econômico, político e sócio-cultural. $^{42}$

Segundo o autor Sérgio Amadeu da Silveira, poder-se-ia dizer que telecentro é considerado a "forma mais ampla de acesso físico ao computador e à Internet". Completando o significado, relata ainda o mesmo autor que "telecentro é um espaço físico em que são colocados alguns computadores conectados à Internet para uso comunitário, em geral gratuito". ${ }^{43}$

Via telecentros, a população menos favorecida poderia ter acesso e contato com algum tipo de tecnologia, permitindo o convívio em uma estrutura social diferenciada; não para transformá-la em uma sociedade informatizada, mas na tentativa de diminuir a distância existente entre aqueles que detêm a informação por possuírem acesso mais direto à tecnologia e aqueles que se mantêm à sua margem.

Porém, mais do que ter acesso ao recurso tecnológico promovido pelo telecentro, a inclusão, como ressaltam Jesus e Mance “... pode ser entendida como o processo ou situação de participação como ator e beneficiário, em contextos de oportunidade de trabalho ou de distribuição da riqueza produzida ou ainda, de políticas públicas. Sua negação, total ou parcial, configuraria um quadro de exclusão."

Sobre esse aspecto, Barreto mostra o objetivo da democratização do acesso à informação, quando afirma que

a nossa crença é que o destino final, o objetivo do trabalho com a informação é promover o desenvolvimento do indivíduo, de seu grupo e da sociedade. Entendemos por desenvolvimento de uma forma ampla, como um acréscimo de bem estar, um novo estágio de qualidade de convivência, alcançado através da informação. A ação social maior é fazer a luz brilhar para cada ser humano através da informação como mediadora do conhecimento".

\footnotetext{
42 DARELLI, Lúcio Eduardo. Telecentro como Instrumento de Inclusão Digital para o e-gov Brasileiro. Florianópolis: Telesc, 2003, p. 26

${ }^{43}$ SILVEIRA, Sérgio Amadeu da. Exclusão Digital - A Miséria na Era da Informação. São Paulo: Editora Fundação Perseu Abramo, 2001.

${ }^{44}$ Revista i-Coletiva. www.icoletiva.com.br.

${ }^{45}$ JESUS, Paulo de; MANCE, Euclides. Exclusão/Inclusão. In: CATTANI, Antônio David (Org.). A Outra Economia. Porto Alegre: Veraz Editores, 2003, p. 149-153.

${ }^{46}$ BARRETO, Aldo de Albuquerque. As Tecnologias Intensivas de Informação e Comunicação e o Reposicionamento dos Atores do Setor. In: INFO 97, 1997, Cuba. Anais... Cuba: 1997, p. 21. 
O telecentro e sua ligação direta com a internet, largamente difundida nos últimos vinte anos como uma base de dados mundial, proporciona diferentes abordagens no tratamento da Sociedade da Informação. Respaldado pela importância e atualidade do tema, quando diversos fóruns mundiais tratam das questões de inclusão digital, inclusão social, sustentabilidade do planeta, nova sociedade da informação, essa ciência vem suportar o objeto de estudo proposto, uma vez que busca compreender os fluxos e reflexos do uso da informação nos diversos campos, dada a sua interdisciplinaridade.

Com esta visão, a pesquisa buscou entender e compreender a política de inclusão digital, trazendo questionamentos e exemplificando com o uso dos telecentros, com o objetivo da melhoria da educação numa perspectiva continuada da criança ao adulto, como forma de inclusão na malha social e na perspectiva laborativa. Não se perde de vista também que as novas tecnologias propiciam navegar num mundo virtual que agrega o lúdico na vida de pessoas que não tem possibilidade econômica ou física de desfrutar de sons, imagens e informações.

O fato de ser a inclusão digital um tema emergente tornou necessário, à sua compreensão, buscar autores e obras que, embora com focos distintos, tivessem como objetivo comum entender o impacto das novas tecnologias, face a Era da Informação, junto aos indivíduos e à educação, enquanto fator essencial na construção e transformação da vida social.

A fundamentação teórica foi sustentada basicamente pelas noções de Inteligência Coletiva, de Pierre Lévy; Educação, de Edgar Morin e Paulo Freire; Exclusão Social, de Stephen Stoer, Ladislau Dowbor e Bernard Sorj. Ainda foram considerados apontamentos de vários outros autores que ajudaram a fundamentar o trabalho.

A apropriação de dados e informações obtida por pesquisas - em um número ainda bem incipiente, que busca mapear a inclusão/exclusão digital no território brasileiro, bem como a análise de algumas iniciativas, em caráter público e privado, para atender a essa situação, também foi alvo desse estudo, com o propósito de ampliar o entendimento sobre seu objeto.

Segundo Edgar Morin ${ }^{47}$, a leitura da realidade apresenta problemas que necessitam de conhecimentos multidisciplinares, pois, somente a partir da identificação do conhecimento pertinente da sua articulação e organização, torna-se possível apontar caminhos que possam promover soluções.

O texto, resultado do processo de análise, surgiu a partir da interlocução entre o teórico e a realidade empírica.

\footnotetext{
${ }^{47}$ MORIN, Edgar. Jornadas Temáticas (1998: Paris, França: 1998). A Religação dos Saberes: o desafio do século XXI / idealizadas e dirigidas por Edgar Morin, tradução e notas, Flávia Nascimento. 2. ed., Rio de Janeiro: Bertrand Brasil, 2002.
} 


\section{CONSIDERAÇÕES FINAIS}

O texto buscou tratar do cenário atual do desenvolvimento da Sociedade da Informação no Brasil e demonstrar que o país tem conquistado avanços no tocante à democratização das tecnologias da informação e comunicação, mas, mesmo assim, constata-se que a inserção plena na Era do Conhecimento ainda é uma realidade em construção. A ampliação do valor da informação aliada às tecnologias convergentes para conceitos digitais força a sociedade atual a se padronizar nas exigências de um novo padrão de vida. Esta mudança causa um impacto econômico-social e representa uma profunda ruptura no modo como a sociedade se organiza, repercutindo na forma potencial de promover a integração e reduzir a distância entre pessoas, além de permitir um patamar significativo de informação.

Este modelo de organização das sociedades assenta num modo de desenvolvimento social e econômico onde a informação, como meio de criação de conhecimento, desempenha um papel fundamental na produção de riqueza e na contribuição para o bem-estar e qualidade de vida de todos. Condição para a Sociedade de a Informação avançar é a possibilidade de todos poderem aceder às tecnologias de informação, presentes no nosso cotidiano que constituem instrumentos valorosos às comunicações pessoais, de empreendedorismo e de lazer. É neste contexto que a pesquisa tem por objeto investigar o papel da educação para a inclusão digital como veículo da inclusão social.

Os fatos escolhidos por este trabalho permitem acolher algumas sugestões de acesso as tecnologias como: facilitação ao acesso a compra de computadores por meio da redução de valores por meio da redução de impostos, e dos juros no financiamento e na compra parcelamento; cursos de capacitação gratuitos fomentados pelo governo ou organizações nãogovernamentais, além de iniciativas vindas de instituições privadas; o acesso a internet gratuita no intuito de proporcionar ao individuo o acesso livre a rede, assim como a política de diminuir os custos de acesso a intenet, além de novas possibilidades advindas da criatividade humana.

Para que o país experimente um desenvolvimento tecnológico significativo são necessárias políticas públicas de curto, médio e longo prazo para as tecnologias da informação e comunicação possam estar solidamente conectadas entre outros aspectos: com a melhoria na formação educacional e profissional, e por consequencia, com a facilitação de espaços para o empreendedorismo, e para a geração de novos postos de trabalho; com a participação ativa do setor privado e de organizações governamentais e não-governamentais nas iniciativas de universalização das tecnologias.

A informação vista como o bem comum que possa ser acessível de forma igualitária a todos: os cidadãos nacionais ou não, os apátridas e os refugiados. Mas, a realidade é outra: no Brasil, o acesso à informação ainda é limitado, mas já se transforma, e o uso de telecentros como forma de realizar inclusão digital, é um exemplo, na medida em que as pessoas lá possuem 
acesso gratuito as tecnologias da informação e comunicação, em especial, a internet, impulsionando-os a pesquisa, o estudo, o desenvolvimento profissional e a participação social. Um telecentro deve ser não só uma forma de capacitação para o acesso, uso e produção de informação, mas, também, à criação de um espaço social e cultural que propicie desfrutar e compreender a realidade para usufruir o que há de bom e também transformar. A exclusão digital é hoje mais uma face das desigualdades sociais. A inclusão digital é um desafio a ser enfrentado no cotidiano, e um dos pressupostos de inclusão social e de participação democrática da sociedade. O mundo atual produz conhecimento de outra forma que a figura do gênio solitário tem poucas chances em nossa sociedade.

\section{REFERÊNCIAS BIBLIOGRÁFICAS}

AGÊNCIA FAPESP. Desigualdades Digitais. Disponível em:

<http://www.agencia.fapesp.br/boletim_dentro.php?id=4672> Acesso em: 20 jul. 2011.

ANDRADE, Sonia A. C. R. Inclusão Digital na Era do Conhecimento: parcerias Público-privadas alavancam a construção do capital Social. Disponível em: $<$ http://www.cinform.ufba.br/vi_anais/docs/SoniaACRDeAndrade.pdf> Acesso em: 20 jul. 2011.

BARRETO, Aldo de Albuquerque. As Tecnologias Intensivas de Informação e Comunicação e o Reposicionamento dos Atores do Setor. In: INFO 97, 1997, Cuba. Anais... Cuba: 1997.

BARROS, Alice Monteiro de. Curso de Direito do Trabalho. 2. ed., São Paulo: LTr, 2006.

BRANDOLINO, Enrique Ricardo. Tele Trabalho. In: VARGAS, Luiz Alberto de; FRAGA, Ricardo Carvalho (Coord.). Avanços e Possibilidades do Direito do Trabalho. São Paulo: LTr, 2005.

CANOTILHO, José Joaquim Gomes. Estado de Direito. Cadernos Democráticos no 7. Fundação Mário Soares. Lisboa: Gradiva, 1998.

CARDOSO, Ruth Correa Leite. A Era da Informação: Economia, Sociedade e Cultura - O Poder da Identidade, Prefácio, obra de Manuel Castells, Volume 2, 5. ed., Editora Paz e Terra.

CASTANHEIRA NEVES, Antonio. Metodologia Jurídica: problemas fundamentais. Coimbra: Coimbra Editora, 1993.

CASTELLS, Manuel. A Sociedade em Rede (A Era da Informação: economia, sociedade e cultura, v. 1). Tradução de Roneide Venâncio Majer; atualização para 6. ed., Jussara Simões. São Paulo: Paz e Terra, 1999.

CASTELLS, Manuel. A Galáxia da Internet: reflexões sobre Internet, Negócios e Sociedade. Lisboa: Fundação Calouste Gulbenkian, 2004. 325p.

CRITELLI, Dulce Mara. In HEIDEGGER, Martin. Todos nós ... ninguém - Um Enfoque Fenomenológico Social. São Paulo: Moraes, 1981.

DARELLI, Lúcio Eduardo. Telecentro como Instrumento de Inclusão Digital para o e-gov Brasileiro. Florianópolis: Telesc, 2003.

DOWBOR, Ladislau. Tecnologias do Conhecimento: Os Desafios da Educação. Petrópolis: Vozes, 2001. 
DUPAS, Gilberto. Ética e Poder na Sociedade da Informação. 2. ed., ver. e ampl. São Paulo: Editora UNESP, 2001.

DUPAS, Gilberto. Economia Global e Exclusão Social. Pobreza, Emprego, Estado e Futuro do Capitalismo. 3. ed., ver. e ampl. São Paulo: Paz e Terra, 1999.

FINCATO, Denise Pires. Teletrabalho: uma análise juslaboral. Revista Justiça do Trabalho, Porto Alegre: HS Editora, nº 236, ago. 2003.

FREIRE, Paulo. Educação como Prática da Liberdade. 23. ed., Rio de Janeiro: Paz e Terra, 1999.

GALIMBERTI, Umberto. Psiche e Techne: o homem na idade da técnica. Tradução: José Maria de Almeida. São Paulo: Paulus, 2006, p. 20-21.

GOUNNET, Jacques. Educação e Mídias. São Paulo: Loyola, 2004.

GOUVEIA, Luis Manuel Borges. "Sociedade da Informação - Notas de Contribuição para uma Definição Operacional”, nov. 2004, Disponível em: Im@ufp.pt,http://ufp.pt/ Imbg. GOUVEIA, Luis Manuel Borges; GAIO, Sofia. "Sociedade da Informação: balanço e oportunidades". Edições Universidade Fernando Pessoa, 2004.

Grupo Telefônica, "A Sociedade da Informação - Presente e Perspectivas", 2002, p. 35.

HASSMANN, Hugo (Org). Redes Digitais e Metamorfose do Aprender. Petrópolis: Vozes, 2005.

HEIDEGGER, Martins. Ser e Tempo. 10. ed., Tradução de Márcia de Sá Cavalcante. Petrópolis: Vozes, 2001.

JARDIM, Carla Carrara da Silva. O Teletrabalho e suas Atuais Modalidades. São Paulo: LTr, 2003.

JESUS, Paulo de; MANCE, Euclides. Exclusão/inclusão. In: CATTANI, Antônio David (Org.). A Outra Economia. Porto Alegre: Veraz Editores, 2003, p. 149-153.

KUMAR, Krishan. "Da Sociedade Pós-industrial à Pós-moderna: novas teorias sobre o mundo contemporâneo". Rio de Janeiro: Jorge Zahar, 1997.

LEMOS, André. Cibercultura, Tecnologia e Vida Social na Cultura Contemporânea. Porto Alegre: Sulina, 2002.

LÉVY, Pierre. A Conexão Planetária: o mercado, o ciberespaço, a consciência. (Trad.) HOMEM, Maria Lúcia; ENTLER, Ronaldo. São Paulo: Ed. 34, 2001.

LIMA JÚNIOR, Jayme Benvenuto. Os Direitos Humanos Econômicos, Sociais e Culturais. Rio de Janeiro: Renovar, 2001.

MEDEIROS, Paulo Henrique Ramos. "Governo Eletrônico no Brasil: aspectos institucionais e reflexos na governança", 2004.

MORIN, Edgar. Jornadas Temáticas (1998: Paris, França: 1998). A Religação dos Saberes: o desafio do século XXI / idealizadas e dirigidas por Edgar Morin, tradução e notas, Flávia Nascimento. 2. ed., Rio de Janeiro: Bertrand Brasil, 2002.

NAZARENO, Cláudio (et.al.). Tecnologias da Informação e Sociedade: o panorama brasileiro. Brasília: Câmara dos Deputados, Coordenação de Publicações, 2006, $187 \mathrm{p}$.

NETTO, Alexandre Annenberg. Infovias. In: CGI.br (Comitê Gestor da Internet no Brasil). Pesquisa sobre o Uso das Tecnologias da Informação e da Comunicação 2008. São Paulo, 2009. 
OST, François. O Tempo do Direito. Porto Alegre: Editor Instituto Piaget, 1999.

PEDREIRA, José Pinho. O Teletrabalho. Revista LTr, São Paulo, v. 64, n 5, maio 2000.

PINTO, José Augusto Rodrigues. Teletrabalho. Revista de Doutrina e Jurisprudência do TRT da 16ª Região, São Luis, v. 13, nº 1, jan./dez., 1994.

PINTO, José Augusto Rodrigues; PAMPLONA FILHO, Rodolfo. Repertório de Conceitos Trabalhistas: Direito Individual. v. 1, São Paulo: LTr, 2000.

PORTO ALEGRE, Prefeitura Municipal. Mapas da Inclusão e Exclusão Social de Porto Alegre. Gabinete do Prefeito/Secretaria do Planejamento Municipal, 2004. Disponível em <http://www.portoalegre.rs.gov.br> Acesso em: 20 jul. 2011.

SCHWARTZ, Gilson. "Exclusão Digital entra na Agenda Econômica Mundial". São Paulo: Folha de S. Paulo, 2000.

SILVA, Frederico Silveira e. O Teletrabalho como Novo Meio de Laborar e sua Compatibilidade com o Ordenamento Jurídico. Revista CEJ, Brasília DF, n 27, 2004, p. 102-109.

SILVEIRA, Sérgio Amadeu da. "O Duplo Combate à Pobreza do Conhecimento e a Necessidade da Alfabetização Tecnológica". In Exclusão Digital: a miséria na era da informação. São Paulo: Editora Fundação Perseu Abramo, 2001.

SILVEIRA, Sérgio Amadeu da. Exclusão Digital - A Miséria na Era da Informação. São Paulo: Editora Fundação Perseu Abramo, 2001.

TOFLLER, Alvin. A Terceira Onda. 16. ed., Rio de Janeiro: Record, [s.d]. p. 200-205.

ZIMERMAN, D. E. Bion: da Teoria à Prática. Uma Leitura Didática. Porto Alegre: Artes Médicas, 1995. 